\title{
Pathways and Processes Linking Social Support to Health: Development of an Exploratory Model With South African Caregivers
}

Qualitative Health Research

202I, Vol. 3I (2) 27I-286

(C) The Author(s) 2020

Article reuse guidelines:

sagepub.com/journals-permissions DOI: $10.1177 / 1049732320966584$

journals.sagepub.com/home/qhr

(SSAGE

\author{
Marisa Casale ${ }^{1,2} \mathbb{1 D}$
}

\begin{abstract}
Despite ample evidence of the protective role of social support for mental and physical health, key gaps remain in our understanding of the pathways and mediating processes explaining these relationships in specific vulnerable populations. The author applies a theoretical framework developed by House et al. to qualitative data, collected with 24 caregivers of children living in HIV-endemic South African communities, to explore potential effects and processes linking social support to health. The data used for this analysis were part of a sequential mixed-methods research study with caregivers of children; previous survey findings $(n=2,477)$ showed significant associations between more social support and better mental health and self-reported physical health. Results point to multiple pathways and biopsychosocial mediating processes possibly explaining the support-health relationship. The author develops an exploratory model to illustrate these findings, based on the House et al. framework, and discusses implications for research, interventions, and theory.
\end{abstract}

\section{Keywords}

social support; mental health; physical health; mediating mechanisms; caregivers; qualitative; directed content analysis; indepth interviews; Southern Africa

\section{Background}

There is no question that social support matters for mental and physical health. A large body of evidence shows positive associations between this functional dimension of social relations and better mental and physical health outcomes, among both ill and healthy individuals. Social support has been found to have a direct (main effect) relationship with mental health (Hill \& Watkins, 2017; Khalid \& Dawood, 2020; Yeji et al., 2014) and to buffer the negative effects of specific stressors, such as poverty or illness, on mental health (Kawachi \& Berkman, 2001; Muzi et al., 2019; Tsai et al., 2016). Arguably the strongest evidence of the relationship between social support and physical well-being is provided by studies that assess mortality risk. A 2010 meta-analysis, covering data from 308,849 individuals over an average of 7.5 years, found participants with stronger relationships, including dimensions of social support, to have a 50\% increased likelihood of survival after taking into account initial health status (Holt-Lunstad et al., 2010). These findings are reinforced by a more recent meta-analysis exposing social isolation as a risk factor for higher mortality (Holt-Lunstad et al.,
2015), and empirical studies showing associations between social support and self-reported physical health or clinical indicators of disease progression (Bekele et al., 2013; Duboz et al., 2017; Umar et al., 2019).

Yet the evidence illustrating how social support may be positively linked to mental and physical health outcomes is less conclusive, although essential to refine theory and design effective interventions (Sarason \& Sarason, 2009; Thoits, 2011). The theoretical and empirical literature suggests that both main and stress-buffering effects of social support may be direct or mediated by biological, psychological, and behavioral processes (House et al., 1988). To date, the evidence is more compelling for mental health outcomes. Studies working with adult populations, including adults living with HIV or

\footnotetext{
'University of the Western Cape, Bellville, South Africa

${ }^{2}$ University of Oxford, Oxford, United Kingdom
}

\section{Corresponding Author:}

Marisa Casale, School of Public Health, University of the Western Cape, Robert Sobukwe Road, Bellville 7535, South Africa.

Emails: maj.casale@icloud.com; mcasale@uwc.ac.za 
other chronic illness, have identified psychological and behavioral processes as significant mediators of the support-mental health relationship. These include psychological resilience indicators, as well as more adaptive and less maladaptive coping processes (Folkman \& Moskowitz, 2004; Liu et al., 2013; Simoni et al., 2005; Thoits, 2011; Yadav, 2010). The relationship between social support, better physical health outcomes, and lower mortality has been linked to positive health behaviors such as healthier eating, exercising, treatment and medication adherence, and health care utilization (Chandran et al., 2019; Greaney et al., 2018; Holt-Lunstad et al., 2010; Uchino, 2006). Moreover, the connection between social support and physical health invariably involves physiological, as well as potential psychological and behavioral, processes. The strongest evidence of physiological explanatory factors is related to cardiovascular function, neuroendocrine function, immune function, and inflammation (Uchino, 2006; Uchino et al., 2018; Uchino \& Way, 2017).

Despite an increase in research conducted to investigate these processes over the past three decades, important gaps remain. These include gaps in our understanding of the links between posited psychological mediators and physiological processes, and the multiple pathways that may be operating simultaneously in the same individuals or population. Scholars have, in fact, proposed more openness to interdisciplinary research refining hypothesized links and models and identifying new mediating mechanisms (Uchino et al., 2012). There is also a clear geographical disparity in global research in this area, as to date most empirical studies have been conducted in high-income countries. In Southern Africa, for example, research on social support and health is scarce, particularly studies investigating pathways that explain observed associations between social support and health outcomes. Yet this type of investigation may be particularly valuable, considering the high burden of HIV and other infectious disease and the growing prevalence of noncommunicable disease in the region (Coetzee et al., 2019; Gouda et al., 2017). Better understanding how social support influences health among specific vulnerable populations in low-resourced settings assumes particular importance, given a greater urgency for effective responses, and considering that mediating processes may vary across diverse populations and contexts (Kawachi \& Berkman, 2001).

Primary caregivers of children in HIV-endemic Southern African communities are a high-risk population for mental and physical health conditions, as a result of health risks related to HIV and caregiving responsibilities in a context of multiple social stressors (Casale \& Wild, 2013; Pinquart \& Sörensen, 2007). Much has been written describing the financial, physical, social, and emotional burden of care associated with informal caregiving in Southern Africa (Kalomo \& Besthorn, 2018; Katana et al., 2020; Mashegoane \& Mohale, 2016; Ntsayagae et al., 2019; Streid et al., 2014). Caregivers, mainly women and often older adults, are caring for their own children and orphaned or other nonbiological children, as well as individuals with illness and disability. They are doing so in a context of poverty, HIV, and other social stressors (Huang et al., 2017; Kalomo \& Besthorn, 2018). Qualitative research conducted in Southern Africa highlights caregivers' feelings of hopelessness, powerlessness, and distress, as they struggle to cope with financial and emotional hardship (Mashegoane \& Mohale, 2016; Ntsayagae et al., 2019). Despite various levels of formal or institutional support, several studies report inadequate formal and informal social support as contributors to caregiver burden (Maddocks et al., 2020; Mashegoane \& Mohale, 2016). Conversely, social support from friends, family, and the community has been highlighted as a key resource for coping and access to health care (Fried et al., 2015; Kiggundu \& Oldewage-Theron, 2009; Maddocks et al., 2020; Streid et al., 2014). A few quantitative studies also show positive associations between higher perceived social support and better mental health outcomes among caregivers of children in sub-Saharan Africa (Casale et al., 2014, 2015; Huang et al., 2017). Yet, these analyses are scarce, and no known quantitative or qualitative study comprehensively investigates the mediating mechanisms potentially explaining positive effects of social support on health in these populations.

The aim of this study is to contribute to the empirical gaps and extension of theory (Hsieh \& Shannon, 2005) in this area. The author applies a theoretical framework developed by House et al. (1988), described in greater detail below, as the lens through which to analyze qualitative data from 24 caregivers of children living in an HIVendemic South African community. A previous linked health survey, conducted in the same community, had found associations between more social support and better mental health and self-reported general health and functioning (Casale et al., 2012, 2014, 2015). The objective of this qualitative study was to explore potential effects and processes linking social support to health in this population, which could be explaining these observed associations. The author explored caregivers' perspectives of how the support they received affected their mental and physical well-being.

\section{Mediating Processes Linking Social Support to Health: Constructs and Theoretical Framework}

Social support has been defined as the "functional nature or quality" of social relationships (House et al., 1988, p. 302 ) in that it encompasses the functions performed for 
an individual by support providers (House et al., 1988; Thoits, 2011). These functions, or "types" of support, are most frequently categorized as emotional (e.g., love, care, and encouragement), instrumental (e.g., providing tangible items or practical assistance), and informational assistance (House et al., 1985). The most commonly cited support providers are significant others, family members and friends (Taylor, 2011). These are, however, context specific and can also include a wide range of other individuals and groups, such as support groups, faith groups and community members.

A model developed by House et al. (1988), referred to as "A framework for research on structures and processes of social relationships in relation to health" (House et al., 1988, p. 303), was used as the conceptual framework to guide this study. It was chosen because of its broad and comprehensive illustration of both the potential effects of social support and the biopsychosocial processes explaining these. This model, illustrated in Figure 1, shows how social support is a key social process and aspect of the functional content of social relationships. It can be linked to health through main or stress-buffering effects, in turn mediated by biological, psychological, or behavioral processes (House et al., 1988). Psychological processes are described as relationships or attachments that may lead people to feel better psychologically or change their perceptions of the world and of stressful situations; this includes the appraisal of stressors and how to cope with these (Lazarus et al., 1974). Behavioral changes, resulting from social relationships, could include health-promoting behaviors or behaviors that are protective of health in threatening situations. Lastly, the impact of social variables on physical, and to some extent mental, health involves biological mechanisms at some point, for example, through cardiovascular effects or other forms of physiological reactivity (House et al., 1988).

\section{Method}

\section{Overall Study Design}

The qualitative research presented in this article is part of an explanatory sequential mixed-methods research design. The first component was a health survey conducted in 2009 and 2010 with 2,477 caregivers of children, including 1,198 caregivers from the urban site where the qualitative study was conducted. ${ }^{1}$ Survey results showed a direct relationship between more social support and a lower likelihood of experiencing symptomatic anxiety (Casale et al., 2014) as well as overall better self-reported general health and functioning (Casale et al., 2012) for the whole sample of caregivers. Social support was also found to moderate the relationship between chronic illness and depression among female caregivers (Casale et al., 2015).
The data presented in this article derive from a subsequent qualitative component of the mixed-methods research. It was conducted to provide further insight on the biopsychosocial mediating processes (House et al., 1988) possibly explaining the associations found between more social support and better health outcomes in the health survey. Moreover, given the particular interest in the role of social support for HIV-positive caregivers, and evidence of greater protective effects of social support for women (Kendler et al., 2005), this qualitative work also aimed to highlight differences in the perspectives of male versus female, and HIV-positive versus HIV-negative, caregivers.

\section{Sampling and Field Research}

In-depth semi-structured interviews were conducted in 2011 and 2012 with 24 primary caregivers of children aged 10 to 17 years, living in an urban township approximately $15 \mathrm{~km}$ from the city of Durban. The study site had been chosen for the previous health survey based on its high HIV prevalence rate $(\geq 30 \%$ HIV prevalence among antenatal clinic attendees; South African Department of Health, 2010), its place among the $20 \%$ most socially challenged wards within the selected urban municipality (as per the provincial health deprivation indices; Noble et al., 2006), and its urban nature.

A sample size of 24 individuals was decided based on available funding and resources for this project. Participants were purposively selected, using sociodemographic and health information from the urban health survey database. The key selection criteria were HIV status and gender; both were based on self-report data from the survey. Since women represented the large majority of caregivers in this community ( $89 \%$ of community survey participants were female), they were also more strongly represented in the qualitative sample. The final sample consisted of 12 HIV-positive and 12 HIV-negative caregivers: eight HIV-positive females and four HIV-positive males, and eight HIV-negative females and four HIVnegative males. All participants were Black African and Zulu was their mother language. Their ages ranged from 31 to 74 years, and nine reported living with a spouse or partner. Only four of the 24 participants had completed high school, only eight were employed at the time, and 12 reported members of their household experiencing hunger at least occasionally. The number of children in the home ranged from one to six, and 15 caregivers were living in households where orphaned children were present.

Guided by the theoretical framework (House et al., 1988), the interview topic guide included broad questions on participants' experiences of anxiety and depression and how they perceived social support to be influencing their mental and physical health. To provide contextual background and 

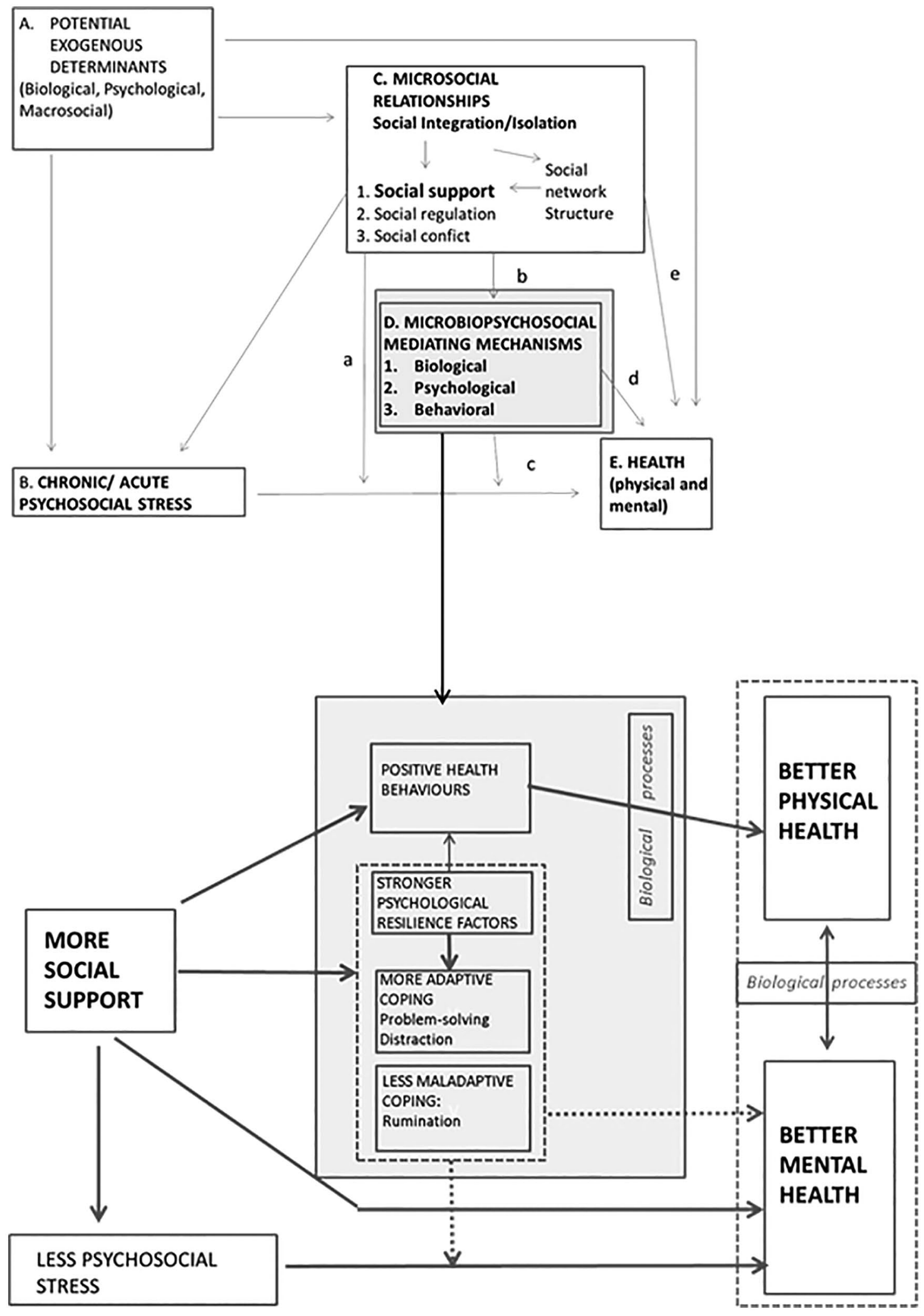

Figure I. Diagrammatic representation of findings, in relation to the House et al. (1988) model. 
put participants at ease, interviewers initiated with general questions, including how long the caregiver had lived in the area and how many children they were caring for. They then defined social support as "support from family, friends, support groups or anyone else. This can include companionship, help with material things such as food or money, advice, information, affection or anything else." Interviewers asked participants whether they thought support was important in their lives, and who were the most important people in their lives who provided support when it was needed. Interviewers then asked more specifically about the perceived relationship between social support received and caregivers' mental and physical health. Initial questions were open ended and standardized across interviews. The following is an example of a set of initial questions for perceived effects of social support on anxiety: Do you ever feel anxious (e.g., worrying a lot, nervous)? What are some of the things that make you feel anxious? Do you think that the type of support you have been telling me about, or any support you receive, can have an effect on this anxiety? If not, why? If yes, how, that is, what is it about this support that has the effects you are telling me about? For physical well-being, participants were asked the following open-ended questions: Do you think this support affects your physical health? If not, why? If yes, how? Responses were then probed and explored further through follow-up questions, to achieve a better understanding of their meaning and obtain greater depth and detail.

Interviews were between 1 and 2 hours in duration and were carried out in the local language (Zulu). The author conducted all interviews with one of two bilingual field research assistants (one male, one female) who had been trained to use open, nonleading questioning techniques. Interviews were recorded, transcribed, and translated into English, and subsequently quality controlled by a second translator. Ethics approval to conduct this research was received from both the University of KwaZulu-Natal and the University of Cape Town. Informed consent was obtained from all study participants, and approval was granted from the relevant municipal and community representatives. Interviewers were trained and experienced in both research ethics and working with HIV-affected families. A referral system was set up in collaboration with the appropriate local social services and child welfare offices for participants who required more extensive support (such as seeing a counselor or attending a clinic). However, no referrals were required during this qualitative study.

\section{Analytic Approach}

A directed content analysis was conducted (Hsieh \& Shannon, 2005), incorporating aspects of deductive and inductive approaches (Neuman, 2006; Ritchie \& Lewis, 2006). A directed approach can be used to test or conceptually extend a theoretical framework; the theory typically helps focus the research questions and determines an initial coding scheme or relationships between codes (Hsieh \& Shannon, 2005). Although the House et al. (1988) model provided a theoretical framework to guide this analysis, the intention was to apply a part exploratory, inductive approach to refine and potentially extend the broad categories provided by the model.

The data analysis was conducted by the author, in consultation with the bilingual interviewers and with researchers from various disciplines. The first part of the analysis was conducted manually. In consultation with the interviewers, the author read through printed transcripts of the interviews multiple times to identify text relevant to the relationships between social support and (physical or mental) health and potential mechanisms explaining these. An initial broad coding framework was then developed based on the main pathways indicated in the House et al. (1988) framework. The transcripts were imported into NVivo software, and the data were coded using these major themes. Where text identified as relevant did not fit well into these predetermined themes, new themes were created.

The themes were then organized into subthemes, drawing from the House et al. (1988) paper and the broader theoretical and empirical literature in the field of social relations and health. The author refined the analytical framework multiple times, through a further, more focused review of the relevant health psychology and sociology literature, and in consultation with various academics. These were individuals working in disciplines including psychology, public health sciences, and social work and social policy, within and beyond the author's research institution. The author also sought to identify dominant and less dominant themes in the data, based on the frequency of their occurrence (Kuckartz, 2014; Ritchie \& Lewis, 2006), as well as differences in perspectives between subgroups of caregivers.

\section{Results}

The final structure of themes and subthemes are illustrated in Table 1 and described in detail below.

\section{Contextual Background: Stressors for Mental Health and Sources of Social Support}

All caregivers reported feeling anxious (e.g., worrying a lot, feeling nervous) or depressed (e.g., sad, upset, or hopeless) at times. The most frequently reported sources of stress were children's bad behavior or delinquency; not being able to meet the children's needs; concerns regarding what would happen to the children when the caregiver passed away; stigma; financial difficulties, the caregiver's own illness; having experienced the illness or death of loved ones. Participants reported receiving both emotional and instrumental support not only from significant 
Table I. Final Thematic Framework.

\begin{tabular}{|c|c|c|}
\hline Main Theme & First-Level Subthemes & Second-Level Subthemes \\
\hline \multirow[t]{2}{*}{ Contextual background } & Caregiver mental health & $\begin{array}{l}\text { - Caregiver experiences of anxiety and depression } \\
\text { - Key stressors causing anxiety and depression }\end{array}$ \\
\hline & Caregiver social support & $\begin{array}{l}\text { - Sources of support } \\
\text { - Types of support considered important for health }\end{array}$ \\
\hline \multirow{3}{*}{$\begin{array}{l}\text { Positive effects of } \\
\text { social support on } \\
\text { mental health }\end{array}$} & Direct effect on mental health & $\begin{array}{l}\text { - Talking about problems } \\
\text { - Advice, comfort, and reassurance }\end{array}$ \\
\hline & $\begin{array}{l}\text { Indirect effect on mental health through } \\
\text { mediating processes }\end{array}$ & $\begin{array}{l}\text { - Psychological resilience factors: hope, optimism, self- } \\
\text { esteem, self-efficacy } \\
\text { - Coping processes: distraction, rumination, and more } \\
\text { active problem solving }\end{array}$ \\
\hline & $\begin{array}{l}\text { Indirect effect on mental health by directly } \\
\text { addressing stressors }\end{array}$ & - Instrumental support with food and money \\
\hline \multirow[t]{2}{*}{$\begin{array}{l}\text { Positive effects of } \\
\text { social support on } \\
\text { physical health }\end{array}$} & $\begin{array}{l}\text { Indirect positive effect through better } \\
\text { mental health }\end{array}$ & $\begin{array}{l}\text { - Changes in perception of pain or ability to affront pain } \\
\text { - Less fatigue } \\
\text { - Better appetite } \\
\text { - Blood pressure regulation }\end{array}$ \\
\hline & $\begin{array}{l}\text { Indirect positive effect through better } \\
\text { health behaviors }\end{array}$ & $\begin{array}{l}\text { - Healthier eating } \\
\text { - Not smoking } \\
\text { - Transport to health facilities } \\
\text { - Support with access to medicine and medication } \\
\text { adherence }\end{array}$ \\
\hline
\end{tabular}

others and family members but also from friends and neighbors, church members, and support groups. Both forms of emotional support (care, comfort, love) and instrumental support (e.g., food, money, health care) were considered equally important and most effective if provided in conjunction.

\section{Themes Explaining Positive Effects of Social Support on Mental Health}

All caregivers perceived social support to have a positive effect on their mental health. Themes identified in the data indicate three ways in which social support was perceived to positively influence mental health: (a) a direct effect on mental health; (b) an indirect effect on mental health, through psychological resilience variables and coping processes; (c) an indirect effect on mental health, as a result of social support reducing or eliminating the stressors affecting mental health. These three themes are described in more detail below.

Direct effect on mental health. One of the dominant themes explaining the beneficial effects of social support on mental health was the emotional "relief" or a sense of emotional "unburdening" experienced after sharing problems with others, and subsequently receiving practical advice, comfort, and reassurance. This theme was taken up mainly by female caregivers. For example, an HIVnegative female caregiver recounted that, when she was depressed, "releasing" this sadness by talking about it and receiving advice helped her feel less sad. She explained, "I have to talk about it if I want it to pass." Other caregivers spoke about being "calmer" and "free in the heart," suggesting a lack of emotional burden:

I feel relieved - even if it would've worried me a lot, and it would have been a burden on my shoulders, but I feel relieved after telling one of them [husband or sister] . . . It won't eat you up alone. (HIV-negative female caregiver)

Several participants also spoke of feeling calmer after obtaining practical advice in relation to specific stressors. This comfort could derive from the caregiver being reassured that he or she was not alone in experiencing particular problems. For example, an HIV-positive female caregiver explained how the practical advice and care received from her sisters, when they visited, helped her feel less anxious:

Because when I tell her [my sister] about the children's treatment towards me she will tell me "you know, children are like that. What you should do is that you should get a grown up child to accompany you to the clinic," so that then I can feel better. After she has given me such advice I feel less anxious.

An HIV-negative male caregiver told how he sometimes felt depressed because of his children's "bad behavior" and his difficulty making ends meet. He explained how encouragement from his wife helped him feel less depressed during these trying times: 
It's when we are able to talk and give each other ideas on how to raise our children ... And the comfort, she will comfort me and tell me that everything will be ok. That I must not lose hope, I will be fine.

Indirect effects on mental health through mediating processes: Psychological resilience factors. Social support was perceived to lead to greater hope and optimism for the future, which in turn helped caregivers feel less anxious or depressed. This was identified as a particularly important theme for HIV-positive individuals. Both HIV-positive and HIV-negative caregivers argued that it was crucial to provide HIV-positive individuals with the hope of survival, of living a relatively "normal" life, of being considered no different to HIV-negative individuals, and of a better future:

I feel sad when I think about my illness, that is when they [my sisters] console me by saying there are lot of people who are sick but they are still alive. And I feel less worried to know that I'm not the only person who is sick . . They encourage and give me hope . . . they advise me not to give up about life and I'm still going to live for a long time. (HIVpositive female)

Another HIV-positive female caregiver told of how attending an HIV support group helped her feel less anxious, by providing her and the other group members with hope and advising members on how to deal with HIVrelated stigma.

They give us hope, love and there is a lot that they provide us with. What can I say, it always feels good . . The support group is the platform where you let out all that makes you sad.

A further, albeit less frequent, explanation given for the positive effect of social support on mental health was that it could boost self-confidence and courage. This theme suggested a positive effect of support on traits associated with resilience, such as self-esteem and self-efficacy (Thoits, 2011). For example, several caregivers spoke about feeling more courageous or in control to confront illness or other stressors, after receiving support. Others explained how emotional support could change the way the caregiver saw himself or herself in relation to others or, as expressed by a male HIV-positive caregiver, "to be able to see yourself exactly like other people who are HIV negative."

Indirect effects on mental health through mediating processes: Coping processes. A further perspective raised repeatedly was that social support could improve mental health by helping caregivers avoid constant negative thoughts and fixating on their problems. This repetitive negative thinking could be defined as "rumination," described as "repetitively thinking about the causes, consequences and symptoms of one's negative affect" and considered a form of maladaptive emotion-focused coping (Nolen-Hoeksema, 1991; Smith \& Alloy, 2009). This theme was raised entirely by ill (and mainly HIV-positive) caregivers in relation to coping with their disease, and predominantly by female caregivers. Caregivers suggested that forms of emotional social support, such as companionship, dialogue, and encouragement, could help HIV-positive individuals avoid repetitively thinking about illness and death:

By attending support groups, one gets to feel relieved, even mentally avoiding thoughts of imminent death, that now I'm HIV positive and I'm going to die. (HIV-positive female caregiver)

Like me, as I'm HIV positive, I don't have to spend most of the time alone, because when you do that you may end up thinking about dying from this disease. (HIV-positive female caregiver)

A further related theme was that of caregivers "forgetting" their concerns as a result of personal interaction and support. This suggested that social support could positively affect participants' mental health through distraction, defined as "focusing attention away from the mood and its causes onto pleasant or neutral stimuli that are engaging enough to present the mind from wandering back to the source of negative affect" (Rusting \& NolenHoeksema, 1998, p. 790). In this case, distraction may be considered an adaptive emotion-focused coping strategy that can reduce emotional distress (Rusting \& NolenHoeksema, 1998). In some cases, the theme of distraction was linked to (less) rumination, suggesting that social interaction and support may to some extent be providing distraction from rumination. The theme of distraction was raised entirely by HIV-positive caregivers, and mainly by female caregivers:

It is better to have company where you can spend time having a conversation instead of think about dying, and so you end up forgetting about it. (HIV-positive female caregiver)

Lastly, the data also suggest that positive effects of support on resilience traits, such as boosting self-efficacy and self-esteem, could lead caregivers to adopt a more active approach to coping with stressors. This could involve, for example, problem solving and/or tackling problems more proactively. More active coping could, in turn, lead to better psychological health. This was not a dominant theme, as only a few caregivers raised it. As one HIV-positive female caregiver explained, referring to support received from people in her social network, 
It makes me feel good about myself and to have more confidence you know, not to run away from problems but to solve them and continue with life.

It was also suggested that support could reduce anxiety or depression by modifying the caregiver's appraisal of the stressor faced, that is, by making the problem appear less daunting and more manageable:

Her [my wife's] support makes me brave, and she would tell me that this is what we need to do, so that we will conquer that situation we are facing together . . I feel relieved and even the thing that was difficult would feel as if it were weakened. (HIV-negative male caregiver)

Indirect effects on mental health by directly addressing stressors. A less frequently raised perspective was that instrumental support could help reduce stress and anxiety caused by the absence of specific items. Examples included tangible support with money or food items that helped to address household food insecurity or improve the family's dwelling. This theme appeared to reflect an indirect positive effect of social support on mental health, by reducing or eliminating stressor(s) contributing to poor mental health. For example, when asked whether the money and food received from others helped her feel less anxious, one female caregiver responded,

It [support received] helps a lot, especially when I'm faced with a particular problem, like worrying about what to eat today, and so I will become happy if the children receive something to eat. (HIV-negative female caregiver)

\section{Themes Explaining Positive Effects of Social Support on Physical Health}

The large majority of participants (23) believed that the support they received had a positive impact on their physical health. Most participants (20) first referred or alluded to better psychological health resulting in better physical well-being. However, caregivers provided additional explanations for effects of support on physical health following further probing. The majority of participants (17) spoke of the effects of social support on health-related behaviors and better access to health-related items or facilities. These themes are described in detail below.

Indirect effects on physical health through better mental health. The data clearly illustrate the perception among (both HIV-positive and HIV-negative) participants that their mental and physical well-being were closely related. Several caregivers associated terms commonly linked with mental health to physical health, or vice versa, for example, feeling "physically relieved." Also, on various occasions, participants answered questions about physical health status by directly referring to mental health status, for example, support positively affecting physical health by relieving one of a sense of burden (helping to feel "emotionally free"), helping with depression, and helping avoid negative thoughts.

Better mental health was also repeatedly linked to physical health symptoms such as lower blood pressure, less fatigue or headaches, experiencing less pain, and (most frequently mentioned) more appetite and weight gain. For example, an HIV-positive female caregiver explained that the financial assistance she received from her employer to improve her living conditions had helped her regain her appetite:

In my body-I was losing weight, because I was not eating well, but now I am gaining and I can see that I am getting back to my normal weight . . . I feel better [on receiving support] because I don't eat when I'm depressed. But my appetite comes back when they encourage and advise me. (HIV-positive female caregiver)

An HIV-negative female caregiver suffering from high blood pressure spoke of how the tangible help she received from her daughter (e.g., assistance with food or chores) led her to feel calmer and less worried and improved her blood pressure. She spoke of her worry being "lifted up" as if this support relieved her of a physical and emotional burden weighing down on her body, and explained, ". . . when I'm frightened my BP goes high."

Three participants also explained that they experienced less physical fatigue when their emotional wellbeing improved as a result of support received. For example, an HIV-negative healthy male participant spoke of how support positively affected his physical health by preventing him from feeling depressed or anxious and making him feel strong. Being worried or depressed was, in turn, related to fatigue, as this excerpt illustrates:

It [support received] makes me very strong and I feel healthy and I don't feel depressed, because there is nothing that worries me emotionally ... When I am worried, I feel tired and I just need to rest, but after that [support] I feel much better.

An elderly female HIV-negative caregiver suffering from diabetes spoke of how emotional support, in the form of dialogue, care, and advice from her sister, made her feel physically stronger and experience less pain. This, despite the fact that she did not receive practical assistance from her family to treat the illness:

It happens that I feel physically better due to feeling better emotionally [after receiving support], especially as someone who is always alone not talking to anybody . . . When I'm 
feeling that way sometimes I forget that I'm sick, even though I can't walk or see but it feels good, like I'm not sick at all.

Similarly, an HIV-positive female caregiver also spoke of how receiving advice and reassurance from members of her church made her feel less stressed and physically stronger, suggesting that she felt less pain or was able to better deal with the pain.

No matter how stressed I was feeling, I feel better [after receiving support from church members] . . I f feel better. I don't feel the pain.

When asked how she felt when she was stressed, the same caregiver responded:

I feel sick and my body doesn't feel okay. I feel tired and suffer from headaches because of the way I think.

A male participant, with a kidney condition that required regular dialysis, told how important the regular support he received from his family and friends was to him. Besides the instrumental help they provided (e.g., with transport to the clinic), he believed their emotional support had been central in helping him remain physically strong, and not giving up on life:

It [support] helps me a lot, because I always have this hope that one day I'll be better, because I have people next to me who are always pushing me, giving me support ... encouraging me all the time, and I think if I didn't have people encouraging me then maybe I wouldn't be here today.

Effects on physical health through more positive health behaviors. Caregivers also spoke of how support provided, mainly by people close to them, led them to engage in more positive and less negative health behaviors. This support mostly took the form of advice and encouragement. However, in some cases, it included tangible assistance, such as buying or cooking healthy foods or facilitating access to health facilities and items. For example, several male caregivers told how their wives' emotional and instrumental support resulted in them leading a healthier life:

You know you get advice from there [your wife], that when you eat you should not just eat greedily ... that to be healthy, I must not be emotionally upset all the time, and that I shouldn't eat a lot. (HIV-negative male caregiver)

Sometimes she [my wife] will bring things that I would not have expected, things that I would be seeing for the first time and they are also healthy things . . . different kinds of vegetables and fruits ... I definitely praise it, because it makes me strong. As you can see me, it's been a while since I last visited a doctor because of sickness. I feel healthy. (HIV-negative male caregiver)
Several male and female caregivers also talked about the importance of support that facilitated access to health care or health-related items. Types of instrumental support included providing or fetching medication, assisting with transport to health facilities, and providing food. For example one HIV-negative male caregiver, who was also a pastor, told how church members gave him money to buy pills or protein tablets, so that his body could "feel healthier." An HIV-positive female caregiver spoke of how her neighbor (her sole support provider) helped her with money for transport, so that she could collect her antiretrovirals (ARVS). Another HIV-positive female caregiver described how her daughter helped her live a healthier life, by ensuring that she was taking the necessary medication and by collecting these medicines herself:

When it is my due date to fetch my medication she [my daughter] asks when was the last time I went for my medication, and when I have found my clinic card she will wake up early in the morning to go pick up my medication.

The young male caregiver with kidney disease highlighted the importance of his friends' and family's support. They took turns to accompany him to the hospital multiple times every week for kidney dialysis:

They are contributing [to my physical wellbeing] very much, because I am dialyzing three times a week: Monday, Wednesday and Friday . . . I can't drive anymore now, it's been two months now that I don't drive. They are always coming three times a week to drive me to hospital and they do this for free. With open hearts.

\section{Discussion}

As indicated above, there was overall consensus among participants that - both instrumental and emotional—social support had positive effects on their mental and physical health. These positive health effects were perceived to occur through various mechanisms, potentially representing coexisting pathways and mediating factors. The pathways and mechanisms identified in this study are represented diagrammatically in the lower model in Figure 1. They will be discussed below in relation to the theoretical framework and broader literature on social support and health.

\section{Diagrammatic Representation of Findings}

Figure 1 contains a diagrammatic representation of the pathways and mediating mechanisms identified in the data connecting social support to mental and physical health. It positions these findings within the House et al. (1988) theoretical framework. The arrow connecting the two models indicates how the multiple mediating processes identified and illustrated in the lower (study) 
model may be seen as an elaboration of the microbiopsychosocial mediating mechanisms box (D) in the House et al. upper model.

The lower model in Figure 1 illustrates the pathways indicated by findings of this study. These include the perceived direct relationship between social support and mental health (second arrow from the bottom), as well as perceived indirect effects through reduced "psychosocial stress" (bottom arrows) and the various psychological and behavioral mediating processes described above, represented in the central box. This model also illustrates how effects of social support on active coping are possibly, in part, explained by psychological resilience variables, such as self-esteem and self-efficacy, whereas the effects on rumination and distraction coping are likely a direct result of support and social interaction. The dashed arrows show potential stress-buffering or main effects of social support on mental health, because it was not possible through this qualitative study to determine the extent to which these processes may be mediating direct versus stress-buffering effects.

The model also illustrates identified indirect pathways linking social support to physical health, through its effects on mental health or better health behaviors. The bidirectional arrow linking mental health to physical health represents both the positive effects of social support on physical health through mental health and the perceived close relationship between mental and physical well-being. A thinner arrow has been included in the diagram to link psychosocial factors to positive health behaviors, given some data supporting the link between psychological resilience factors (e.g., hope or selfesteem) and positive health behaviors. The two boxes in the diagram indicating biological processes serve to illustrate that biological processes would have to occur in at least two points (House et al., 1988; Uchino et al., 2012): between positive health behaviors and physical health outcomes, and between mental health and physical health outcomes.

\section{Discussion of Findings in Relation to the Literature on Social Support and Health}

It is noteworthy that many of the individual mediating mechanisms and pathways identified in this study, and illustrated in Figure 1, resonate with theoretical work or findings of previous empirical quantitative studies conducted with HIV-positive and broader adult populations. Findings of this study point to both direct and mediated pathways between social support and health outcomes, consistent with seminal theoretical literature (Barrera, 1986; House et al., 1988) and numerous empirical studies conducted over the past four decades. Findings pertaining to positive effects on mental health and physical health, respectively, are discussed below in relation to the broader literature, as is the unique contribution of this study.

Positive effects of social support on mental health. The direct pathway identified between social support and mental health (through dialogue) recalls the psychological literature documenting the mental health benefits of talking or writing about experiences and concerns or putting feelings into words (Lieberman et al., 2007; Pennebaker, 1993). This is also supported by evidence of neurocognitive pathways (Lieberman et al., 2007). Instead, the finding that more social support may lead to less distress by preventing stressful events from occurring is not in itself an example of a biopsychosocial mediating mechanism (and is not represented as such in the lower model in Figure 1) but is consistent with what has been defined as the stress prevention model (Barrera, 1986).

Moreover, many of the individual mediating factors emerging from the data to explain indirect effects of social support on mental health have been found to be statistically significant mediators in quantitative studies conducted with caregivers, HIV-affected individuals, or broader adult populations in other parts of the world. For example, self-esteem has been found to mediate the relationship between social support and better mental health among older adults (Kim \& Thomas, 2019), and self-efficacy has been identified as a mediator among people living with HIV (Liu et al., 2013). Studies with HIV-positive individuals (though not conducted in Africa) have identified psychological mediators such as hope, optimism, and coping processes (Liu et al., 2013; Sabina et al., 2019; Schmitz \& Crystal, 2000; Yadav, 2010).

Findings of this study also point to processes or pathways that may be especially important for mental health among specific population groups. For example, hope emerged as a key factor for HIV-positive caregivers. Coping processes such as rumination and distraction, as well as the benefits of talking to others about one's problems, appeared to be more important for female caregivers, and may be central to understanding potential gender differences in protective effects of support on mental health. Consistent with findings of this study, ruminative thinking has been found to be more common among women (Butler \& Nolen-Hoeksema, 1994; NolenHoeksema et al., 1994), and social support has been found to reduce the tendency to ruminate (Nolen-Hoeksema, 1991; Nolen-Hoeksema et al., 1994). It has been argued that social isolation may increase rumination because of the absence of people to provide distraction from rumination, challenge an individual's ruminative thoughts, or encourage engagement in active coping strategies (NolenHoeksema et al., 1994). Distracting external stimuli have, however, been found to relieve depressed mood, reduce 
stress and anxiety, and increase pain tolerance (NolenHoeksema et al., 1994; Stone et al., 1995).

Other qualitative research with South African women living with HIV has shown how ruminating thoughts can worsen depression related to stigma, poverty, and other stressful life events, whereas social support can be a key coping strategy (Petersen et al., 2013). Authors of a South African qualitative study with rural women living with HIV/AIDS argue that avoidance of, escaping from, or minimizing HIV/AIDS could be considered adaptive in a context of limited resources and gender inequalities, where active coping strategies may be limited (Dageid \& Duckert, 2008). Further understanding the dynamics between support, rumination, distraction, and mental health among HIV-positive and other ill adults in Southern Africa should be one key focus for future psychological research. It should also be noted that, although less common, rumination has been associated with positive psychological responses to stressors in some cases, suggesting that different subcomponents of rumination (reflection vs. brooding, for example) may exert different influences on psychological well-being (Smith \& Alloy, 2009; Soo \& Sherman, 2015). Although positive effects of rumination were not identified in this study, future work could usefully investigate both its potential positive and negative dimensions.

Positive effects of social support on physical health. The themes of mental and physical health being closely connected and of social support positively influencing physical health through mental health are in line with a large body of literature documenting the strong relationship between mental and physical well-being (Ohrnbergera et al., 2017; Prince et al., 2007). They also resonate with studies showing measures of mental health to mediate the relationship between social support and self-reported health or health-related quality of life, including among people living with HIV (Bekele et al., 2013; Xiaowen et al., 2018). Findings of social support leading to healthier lifestyle choices, better medication adherence, and greater health access are also in line with findings of studies conducted with HIV-positive and broader adult populations (Chandran et al., 2019; Gentz et al., 2017; Greaney et al., 2018) and research showing health behaviors to mediate effects of mental health on physical health (Ohrnbergera et al., 2017). Although participants did not explicitly discuss links between more positive health behaviors and physical health outcomes, these are easily supported by existing literature on risk and protective behaviors for health (Critchley \& Capewell, 2003; HoltLunstad et al., 2010; Prince et al., 2007). Moreover, other studies have found effects of social support on health behaviors to be mediated by psychological factors associated with resilience. For example, self-efficacy has been found to mediate the relationship between greater social support and treatment adherence among HIV-positive youth (MacDonell et al., 2016).

As indicated above, effects of social support on physical health will at some point involve biological processes. There was some reference in the data to certain physiological processes or symptoms (e.g., appetite, fatigue, blood pressure), which could be, in part, explaining indirect physical health effects of social support through better mental health. Of course, it is difficult to obtain a precise understanding of biological processes through this type of investigation, although findings can point to pathways and indicators to be assessed in future biomedical research. As previously indicated, evidence of physiological explanatory factors linking social support to better physical health outcomes points to cardiovascular function, neuroendocrine function, immune function, and inflammation (Uchino, 2006; Uchino et al., 2018; Uchino \& Way, 2017). Also, the mental health benefits of communicating feelings and problems have been linked to positive neurological effects and other physical health benefits (Kaplan-Solms \& Solms, 2000; Pennebaker, 1993).

Nevertheless, there is clearly still much scope to further investigate biological processes and the pathways explaining effects of social support on physical health in similar populations. This would likely be best achieved through longitudinal, quantitative, or mixed-methods studies that link psychological, behavioral, and biomedical data at multiple time points. Disaggregated analyses by gender could also be of value. Better health behaviors resulting from social support or a form of positive social control appeared to be particularly important for male caregivers in this study. Broader research indicates potential gender differences in risk behaviors for health and their social and psychological determinants, although the evidence is not clear-cut (Ohrnbergera et al., 2017; Vlassoff, 2007; Wu et al., 2006).

Unique contribution of this study. Although many individual mediating mechanisms identified in this study resonate with existing theoretical or empirical work, the findings of this qualitative study add further depth to the existing evidence on support-health mediating processes for this population of caregivers of children in Africa (Kawachi \& Berkman, 2001; Li et al., 1997). Most quantitative studies indicated above investigate one pathway connecting social support and health outcomes, and a few selected mediators at most. The use of qualitative methods for this research has, instead, allowed for rich data describing multiple channels through which social support may be influencing health simultaneously. It has also generated in-depth data that provide context, for example, by linking mediating processes to specific experiences, stressors, and support providers. 
Findings of this work suggest the possible coexistence of several causal pathways involving multiple psychological and behavioral factors, represented by the box labeled "biopsychosocial processes" in the House et al. model (see Figure 1). These findings in fact reinforce the importance of simultaneously measuring and exploring multiple mediating variables in mixed-methods analyses (House et al., 1988; Uchino et al., 2012). Further research would be necessary both to test these pathways statistically and to determine whether similar combinations of pathways and mediating processes exist in similar and different populations. This would also allow for a greater understanding of which mediating processes are explaining main effects and stress-buffering effects for key stressors in specific populations (Thoits, 2011).

\section{Study Limitations and Reflexivity}

There are several important limitations to this analysis. Despite probing, participants may not have provided an exhaustive list of perceived pathways or mediating factors explaining the support-health relationship. Also, as specified above, this research does not allow us to determine which pathways or mediating processes are explaining stress-buffering or main effects or both, or to clearly define biological processes. These objectives are best left to quantitative mediation and moderation models, and biomedical research. Also, although the focus of this study was on effects of social support on health, it is of course possible for physical and mental health to influence social interaction (Ohrnbergera et al., 2017) or for these relationships to be bidirectional. Although beyond the scope of this study, future research could further explore this potential bidirectionality.

Moreover, it is recognized that the researchers' characteristics, knowledge, and views will influence the research process to some extent. In this particular case, the author played a key role in the instrument design, data collection, and analysis. The author is a female South African of European descent, born in KwaZulu-Natal into a middleincome family, who had completed postgraduate studies and was in her late thirties at the times of the interviews. The author's education level, socioeconomic status, and race (Giliomee \& Schlemmer, 1989) may have increased the power differential between herself and most (male and female) caregivers. However, the author's age (below the average age of caregivers interviewed at the time) and gender may have reduced this power differential, and allowed her to more closely relate to female caregivers. Recognizing that this may have had the opposite effect for male caregivers, the author conducted all male caregiver interviews with a male bilingual interviewer. Moreover, the author's in-depth knowledge of the empirical and theoretical literature in this area could be seen as a strength, but at the same time could have influenced the follow-up or probing questions asked of participants.

Given the limited resources available to conduct this qualitative study, the author was the only researcher working on the study for its entirety and conducting the data analysis. The author, therefore, sought to minimize the risk of bias by discussing the interview content and findings with the two Zulu bilingual interviewers, who were able to clarify and provide further insight on meaning and interpretation. She also obtained feedback on the data interpretation and thematic framework from various researchers across disciplines (as described above). It should also be noted that the author had spent several months working in the same community on a household survey and engaging with community stakeholders prior to conducting this qualitative research.

\section{Conclusion}

Findings of this study reinforce the value of social support as a resource for mental and physical health among caregivers and HIV-affected individuals, in Southern Africa and beyond. Moreover, these findings provide further insight into the multiple intervening and potentially coexisting pathways that may be explaining supporthealth links in this population (House et al., 1988).

There is, however, considerable further scope for future research in Southern Africa, where the knowledge gap in this field is glaring. For example, there are no known empirical studies quantitatively investigating complete pathways between social support and health with caregivers or HIV-positive individuals in Africa, despite studies showing positive associations in these populations (Casale et al., 2014; West et al., 2019). This highlights the potential for future mixed-methods research in this area and for this exploratory model to contribute to informing this research. Several possible foci for future research have already been discussed above. These include the mediating role of specific psychological resilience and coping mechanisms and the physiological processes explaining changes in physical health. But, more broadly, shedding further light on these phenomena would best be achieved through a combination of (a) longitudinal quantitative studies applying focused social support and health survey tools, and simultaneously testing multiple mediating mechanisms and pathways with representative samples; and (b) linked qualitative work providing further insight on the support context and additional pathways to assess.

From a public health perspective, it would be useful to focus on mediators of relevance for support interventions aimed at addressing key social stressors or public health priorities in the Southern African region. This could include research on the types of support that encourage 
HIV treatment retention and how these would operate. These questions may be particularly salient given high loss to HIV treatment follow-up especially among young adults (Casale et al., 2019) and evidence of positive associations between social support, mental health, and treatment adherence (Gentz et al., 2017; Umar et al., 2019; West et al., 2019). Results of this study, for example, reinforce the importance of strengthening resourcefulness factors and coping responses that are more beneficial for health, reducing social isolation, and improving access to health resources, among individuals living with HIV or other illness (Lazarus et al., 1974; Thoits, 2011; Yadav, 2010). Moreover, emotional support through support groups, transport to health facilities, reminders to take medication, and support with medicine collection were some of the types of support that emerged from this study as useful for medication adherence and health service access.

Overall, attempts to translate evidence of positive effects of (informal) social support into effective support interventions have in some cases been successful and in others less so (Casale \& Wild, 2013; Holt-Lunstad, 2018). This could be, in part, explained by the timing and duration of interventions and an inadequate focus on providers or relationship quality (Holt-Lunstad, 2018). Research providing a more in-depth understanding of the support context and what it is about social support that works (Sarason \& Sarason, 2009) can, however, contribute to informing intervention development.

Lastly, part of the purpose of this study was to apply the House et al. (1988) framework and potentially extend the theory and thinking in this area. The model appeared to work well as a guiding framework for this type of research, focusing on individual-level social and psychological processes. It was sufficiently comprehensive to encompass all identified pathways and mediating mechanisms, and to allow for further extension and refinement of the model through the identification of specific mediating mechanisms and their interaction in this population. It should, however, be noted that this framework is likely to be less suitable for a systems analysis at various levels, without further development. For example, in a recent review of the importance of social relationships for physical health, Holt-Lunstad (2018) suggests applying a social ecological model to identify pathways at the family, community, and society-as well as individual-levels (Bronfenbrenner, 1979; Holt-Lunstad, 2018) to increase the public health relevance of this type of research. This would indeed be an important extension of the current evidence and approaches, but it would require further development of existing conceptual frameworks and research designs. The House et al. model could be deemed innovative for its time, because it considers social support and social relations not only as determinants of health but also determined by macro-social structures and processes (e.g., population trends, social policy, and social inequality). However, the framework does not go beyond recognizing the potential influence of these phenomena and more work would need to be done to adapt it for investigation connecting these various levels. Nonetheless, a noted strength of the ecological model is that it allows for a broader perspective "without sacrificing the detail-oriented precision of a levels approach" (Holt-Lunstad, 2018, p. 441). Even within a broader systems approach, in-depth research that better defines mechanisms linking individual social relations to health in specific populations can make a valuable contribution to the literature, by further illuminating a piece of the bigger picture.

\section{Acknowledgments}

The author acknowledges the important contribution of the field researchers who worked on this project, and thanks the caregivers who agreed to participate in this study.

\section{Declaration of Conflicting Interests}

The author declared no potential conflicts of interest with respect to the research, authorship, and/or publication of this article.

\section{Funding}

The author disclosed receipt of the following financial support for the research, authorship, and/or publication of this article: This work was generously funded by the Health Economics and HIV and AIDS Research Division (HEARD) at the University of KwaZulu-Natal, South Africa.

\section{ORCID iD}

Marisa Casale (iD) https://orcid.org/0000-0002-9258-1927

\section{Note}

1. The survey research was a partnership between the University of KwaZulu-Natal, the University of Oxford, Brown University, and various South African government departments, universities, and nongovernmental organizations; its primary objective was to identify risk and protective factors for the health of children and caregivers in households affected by HIV (see www.youngcarers.org.za).

\section{References}

Barrera, M. (1986). Distinctions between social support concepts, measures and models. American Journal of Community Psychology, 14, 413-445. https://doi. org/10.1007/BF00922627

Bekele, T., Rourke, S., Tucker, R., Greene, S., Sobota, M., \& Koornstra, J., ... The Positive Spaces Healthy Places Team. (2013). Direct and indirect effects of perceived social support on health-related quality of life in persons living with HIV/AIDS. AIDS Care, 25(3), 337-346. https://doi.org/10. 1080/09540121.2012.701716 
Bronfenbrenner, U. (1979). The ecology of human development. Harvard University Press.

Butler, L., \& Nolen-Hoeksema, S. (1994). Gender differences in responses to depressed mood in a college sample. Sex Roles, 30(5-6), 331-346. https://doi.org/10.1007/ BF01420597

Casale, M., Carlqvist, A., \& Cluver, L. (2019). Recent interventions to improve retention in HIV care and adherence to antiretroviral treatment among adolescents and youth: A systematic review. AIDS Patient Care and STDs, 33(6), 237-252. https://doi.org/10.1089/apc.2018.0320

Casale, M., \& Wild, L. (2013). Effects and processes linking social support to caregiver health among HIV/ AIDS-affected carer-child dyads: A critical review of the empirical evidence. AIDS and Behavior, 17(5), 1591-1611. https://doi.org/10.1007/s10461-012-0275-1

Casale, M., Wild, L., Cluver, L., \& Kuo, C. (2014). The relationship between social support and anxiety among caregivers of children in HIV-endemic South Africa. Psychology, Health and Medicine, 19(4), 490-503. https://doi.org/10.1 080/13548506.2013.832780

Casale, M., Wild, L., Cluver, L., \& Kuo, C. (2015). Social support as a protective factor for depression among women caring for children in HIV-endemic South Africa. Journal of Behavioral Medicine, 38(1), 17-27. https://doi. org/10.1007/s10865-014-9556-7

Casale, M., Wild, L., Kuo, C., \& Cluver, L. (2012, July). The relationship between social support and self-reported health among HIV-positive and HIV-negative caregivers of children in two HIV-endemic South African communities [Paper presentation]. XIX International AIDS Conference, Washington, DC, United States.

Chandran, A., Benning, L., Rashelle, M., Wilson, T., Milam, J., Adedimeji, A., . . . Golub, E. (2019). The longitudinal association between social support on HIV medication adherence and healthcare utilization in the Women's Interagency HIV Study. AIDS and Behavior, 23(8), 2014-2024. https:// doi.org/10.1007/s10461-018-2308-x

Coetzee, L., Bogler, L., De Neve, J.-W., Bärnighausen, T., Geldsetzer, P., \& Vollmer, S. (2019). HIV, antiretroviral therapy and non-communicable diseases in sub-Saharan Africa: Empirical evidence from 44 countries over the period 2000 to 2016. JIAS, 22(7), e25364. https://doi. org/10.1002/jia2.25364

Critchley, J., \& Capewell, S. (2003). Mortality risk reduction associated with smoking cessation in patients with coronary heart disease: A systematic review. JAMA, 290(1), 86-97. https://doi.org/10.1001/jama.290.1.86

Dageid, W., \& Duckert, F. (2008). Balancing between normality and social death: Black, rural, South African women coping with HIV/AIDS. Qualitative Health Research, 18(2), 182-195. https://doi.org/10.1177/1049732315575315

Duboz, P., Boëtsch, G., Gueye, L., \& Macia, E. (2017). Selfrated health in Senegal: A comparison between urban and rural areas. PLOS ONE, 12(9), Article e0184416. https:// doi.org/10.1371/journal.pone.0184416

Folkman, S., \& Moskowitz, J. (2004). Coping: Pitfalls and promise. Annual Review of Psychology, 55, 745-774. https://doi.org/10.1146/annurev.psych.55.090902.141456
Fried, J., Harris, B., Eyles, J., \& Moshabela, M. (2015). Acceptable care? Illness constructions, healthworlds, and accessible chronic treatment in South Africa. Qualitative Health Research, 25, 622-635. https://doi.org/10.1177 $/ 1049732315575315$

Gentz, S., Romano, I., Martínez-Arias, R., \& Ruiz-Casares, M. (2017). Predictors of mental health problems in adolescents living with HIV in Namibia. Child \& Adolescent Mental Health, 22(4), 179-185. https://doi.org/10.1111/ camh. 12247

Giliomee, H., \& Schlemmer, L. (1989). From apartheid to nation building. Oxford University Press.

Gouda, H., Charlson, F., Sorsdahl, K., Ahmadzada, S., Ferrari, A., Erskine, H., . . . Whiteford, H. (2017). Burden of noncommunicable diseases in sub-Saharan Africa, 1990-2017: Results from the Global Burden of Disease Study 2017 The Lancet Global Health, 7, e1375-e1387. https://doi. org/10.1016/s2214-109x(19)30374-2

Greaney, M., Puleo, E., Sprunck-Harrild, K., Haines, J., Houghton, S., \& Emmons, K. (2018). Social support for changing multiple behaviors: Factors associated with seeking support and the impact of offered support. Health Education and Behavior, 45(2), 198-206. https://doi.org/1 $0.1177 \% 2 \mathrm{~F} 1090198117712333$

Hill, E., \& Watkins, K. (2017). Women with ovarian cancer: Examining the role of social support and rumination in posttraumatic growth, psychological distress, and psychological well-being. Journal of Clinical Psychology in Medical Settings, 24(1), 47-58. https://doi.org/10.1007/ s10880-016-9482-7

Holt-Lunstad, J. (2018). Annual review of psychology. Why social relationships are important for physical health: A systems approach to understanding and modifying risk and protection. Annual Review of Psychology, 2018(69), 437-458. https://doi.org/10.1146/annurev-psych-122216011902

Holt-Lunstad, J., Smith, T., Baker, M., Harris, T., \& Stephenson, D.(2015). Loneliness and social isolation as risk factors for mortality: A meta-analytic review. Perspectives on Psychological Science, 10, 227-237. https://doi.org/10. $1177 / 1745691614568352$

Holt-Lunstad, J., Smith, T., \& Layton, B. (2010). Social relationships and mortality: A meta-analysis. PLOS Medicine, 7, Article e1000316. https://doi.org/10.1371/journal.pmed. 1000316

House, J. S., Kahn, R. L., McLeod, J. D., \& Williams, D. (1985). Measures and concepts of social support. In S. Cohen \& S. L. Syme (Eds.), Social support and health (pp. 83-108). Academic Press.

House, J., Umberson, D., \& Landis, K. (1988). Structures and processes of social support. Annual Review of Sociology, 14, 293-318. https://doi.org/10.1146/annurev. so. 14.080188 .001453

Hsieh, H.-F., \& Shannon, S. (2005). Three approaches to qualitative content analysis. Qualitative Health Research, 15(9), 1277-1288. https://doi.org/10.1177\%2F1049732305276687

Huang, K.-Y., Abura, G., Theise, R., \& Nakigudde, J. (2017). Parental depression and associations with parenting and children's physical and mental health in a sub-Saharan African 
setting. Child Psychiatry and Human Development, 48(4), 517-527. https://doi.org/10.1007/s10578-016-0679-7

Kalomo, E., \& Besthorn, F. (2018). Caregiving in Sub-Saharan Africa and older, female caregivers in the era of HIV/AIDS: A Namibian perspective. GrandFamilies: The Contemporary Journal of Research, Practice and Policy, 5(1). https://scholarworks.wmich.edu/grandfamilies/vol5/iss 1/6

Kaplan-Solms, K., \& Solms, M. (2000). Clinical studies in neuro-psychoanalysis. Karnac.

Katana, P., Abubakar, A., Nyongesa, M., Ssewanyana, D., Mwangi, P., Newton, C., \& Jemutai, J. (2020). Economic burden and mental health of primary caregivers of perinatally HIV infected adolescents from Kilifi, Kenya. BMC Public Health, 20(1), 1-9. https://doi.org/10.1186/s12889020-8435-0

Kawachi, I., \& Berkman, L. (Eds.). (2001). Social ties and mental health. Journal of Urban Health, 78(3), 458-467. https://doi.org/10.1093/jurban/78.3.458

Kendler, K., Myers, J., \& Prescott, C. (2005). Sex differences in the relationship between social support and risk for major depression: A longitudinal study of opposite-sex twin pairs. The American Journal of Psychiatry, 162(2), 250-256. https://doi.org/10.1176/appi.ajp.162.2.250

Khalid, A., \& Dawood, S. (2020). Social support, self-efficacy, cognitive coping and psychological distress in infertile women. Archives of Gynecology \& Obstetrics, 302(2), 423-430. https://doi.org/10.1007/s00404-020-05614-2

Kiggundu, E., \& Oldewage-Theron, W. (2009). Coping: A challenge for guardians of children orphaned by HIV/AIDS in a South African township. Development Southern Africa, 26(3), 383-397. https://doi.org/10.1080 /03768350903086754

Kim, S., \& Thomas, P. (2019). Direct and indirect pathways from social support to health? The Journals of Gerontology: Series B, 74(6), 1072-1080. https://doi.org/10.1093/geronb /gbx084

Kuckartz, U. (2014). Qualitative text analysis: A guide to methods, practice \& using software. Sage.

Lazarus, R., Averill, J., \& Opton, E. (1974). The psychology of coping: Issues of research and assessment. In G. Coelho, D. Hamburg, \& J. Adams (Eds.), Coping and adaptation (pp. 95-107). Basic Books.

Li, L., Seltzer, M., \& Greenberg, J. (1997). Social support and depressive symptoms: Differential patterns in wife and daughter caregivers. Journals of Gerontology Series B: Psychological Sciences and Social Sciences, 52(4), S200S211. https://doi.org/10.1093/geronb/52b.4.s200

Lieberman, M., Eisenberger, N., Crockett, M., Tom, S., Pfeifer, J., \& Way, B. (2007). Putting feelings into words: Affect labeling disrupts amygdala activity in response to affective stimuli. Psychological Science, 18(5), 421-428. https://doi. org/10.1111/j.1467-9280.2007.01916.x

Liu, L., Pang, R., Sun, W., Wu, M., Qu, P., Lu, C., \& Wang, L. (2013). Functional social support, psychological capital, and depressive and anxiety symptoms among people living with HIV/AIDS employed full-time. BMC Psychiatry, 13(1), 1-23. https://doi.org/10.1186/1471-244X-13-324

MacDonell, K., Jacques-Tiura, A., Naar, S., Fernandez, M., \& ATN 086/106 Protocol Team. (2016). Predictors of self-reported adherence to antiretroviral medication in a multisite study of ethnic and racial minority HIV-positive youth. Journal of Pediatric Psychology, 41(4), 419-428. https://doi.org/10.1093/jpepsy/jsv097

Maddocks, S., Moodley, K., Hanass-Hancock, J., Cobbing, S., \& Chetty, V. (2020). Children living with HIV-related disabilities in a resource-poor community in South Africa: Caregiver perceptions of caring and rehabilitation. AIDS Care, 32(4), 471-479. https://doi.org/10.1080/09540121. 2019.1654076

Mashegoane, S., \& Mohale, N. (2016). Parenting AIDSorphaned grandchildren: Experiences from Lephalale, South Africa. Gender \& Behaviour, 14(1), 6931-6943.

Muzi, N., Miller, M., Ballard, T., Mitchell, D., Hung, Y., \& Melgar-Quiñonez, H. (2019). Does social support modify the relationship between food insecurity and poor mental health? Evidence from thirty-nine sub-Saharan African countries. Public Health Nutrition, 22(5), 874-881. https:// doi.org/10.1017/S136898001800277X

Neuman, W. (Ed.). (2006). Social research methods: Qualitative and quantitative approaches (7th ed.). Pearson Education.

Noble, M., Babita, M., Barnes, H., Dibben, C., Magasela, W., Noble, S. N. P., . . . Zungu, S. (2006). The provincial indices of multiple deprivation for South Africa 2001. Centre for the Analysis of South African Social Policy, University of Oxford.

Nolen-Hoeksema, S. (1991). Responses to depression and their effects on the duration of depressive episodes. Journal of Abnormal Psychology, 100(4), 569-582. https://doi. org/10.1037//0021-843x.100.4.569

Nolen-Hoeksema, S., Parker, L., \& Larson, J. (1994). Ruminative coping with depressed mood following loss. Journal of Personality and Social Psychology, 67(1), 92104. https://doi.org/10.1037/0022-3514.67.1.92

Ntsayagae, E., Poggenpoel, M., \& Myburgh, C. (2019). Experiences of family caregivers of persons living with mental illness: A meta-synthesis. Curationis, 42(1), Article a1900. https://doi.org/10.4102/curationis.v42i1.1900

Ohrnbergera, J., Ficher, E., \& Sutton, M. (2017). The relationship between physical and mental health: A mediation analysis. Social Science \& Medicine, 195, 42-49. https:// doi.org/10.1016/j.socscimed.2017.11.008

Pennebaker, J. (1993). Putting stress into words: Health, linguistic and therapeutic implications. Behaviour Research and Therapy, 31(6), 539-548. https://doi.org/10.1016/00057967(93)90105-4

Petersen, I., Hanass Hancock, J., Bhana, A., \& Govender, K. (2013). Closing the treatment gap for depression comorbid with HIV in South Africa: Voices of afflicted women. Health, 5(3A), 557-566. https://doi.org/10.4236/ health.2013.53A074

Pinquart, M., \& Sörensen, S. (2007). Correlates of physical health of informal caregivers: A meta-analysis. Journals of Gerontology Series B: Psychological Sciences and Social Sciences, 62(2), 126-137. https://doi.org/10.1093/ geronb/62.2.p126

Prince, M., Patel, V., Saxena, S., Maj, M., Maselko, J., Phillips, M., \& Rahman, A. (2007). No health without mental health. The Lancet, 370(9590), 859-877. https://doi.org/10.1016/ S0140-6736(07)61238-0 
Ritchie, J., \& Lewis, J. (Eds.). (2006). Qualitative research practice: A guide for social science students and researchers. Sage.

Rusting, C., \& Nolen-Hoeksema, S. (1998). Regulating responses to anger: Effects of rumination and distraction on angry mood. Journal of Personality and Social Psychology, 74(3), 790-803. https://doi.org/10.1037//00223514.74.3.790

Sabina, S., Shibanuma, A., Poudel, K., Nanishi, K., Koyama Abe, M., . . . Jimba, M. (2019). Perceived social support, coping, and stigma on the quality of life of people living with HIV in Nepal: A moderated mediation analysis. AIDS Care, 31(4), 413-420. https://doi.org/10.1080/09540121.2 018.1497136

Sarason,I., \& Sarason, B. (2009). Social support:Mapping the construct. Journal of Social and Personal Relationships, 26(1), 113-120. https://doi.org/10.1177/0265407509105526

Schmitz, M., \& Crystal, S. (2000). Social relations, coping, and psychological distress among persons with HIV/AIDS. Journal of Applied Psychology, 30(4), 665-685. https://doi. org/10.1111/j.1559-1816.2000.tb02818.x

Simoni, B., Montoya, H., Huang, B., \& Goodry, E. (2005). Social support and depressive symptomatology among HIV-positive women: The mediating role of self-esteem and mastery. Women \& Health, 42(4), 1-15. https://doi. org/10.1300/J013v42n04_01

Smith, J., \& Alloy, L. (2009). A roadmap to rumination: A review of the definition, assessment, and conceptualization of this multifaceted construct. Clinical Psychology Review, 29(9), 116-128. https://doi.org/10.1016/j.cpr. 2008.10.003

Soo, H., \& Sherman, K. (2015). Rumination, psychological distress and post-traumatic growth in women diagnosed with breast cancer. Psycho-Oncology, 24(1), 70-79. https://doi. org/10.1002/pon.3596

South African Department of Health. (2010). The national antenatal sentinel HIV and syphilis prevalence survey. http:// www.doh.gov.za/docs/reports/2011/hiv_aids_survey.pdf

Stone, A., Kennedy-Moore, E., \& Neale, J. (1995). Association between daily coping and end-of-day mood. Health Psychology, 14(4), 341-349. https://doi.org/10.1037/02786133.14.4.341

Streid, J., Harding, R., Agupio, G., Dinat, N., Downing, J., Gwyther, L., . . . Selman, L. (2014). Stressors and resources of caregivers of patients with incurable progressive illness in sub-Saharan Africa. Qualitative Health Research, 24(3), 317-328. https://doi.org/10.1177/1049732314523682

Taylor, S. (2011). Social support: A review. In N. Friedman (Ed.), The Oxford handbook of health psychology (pp. 189214). Oxford University Press.

Thoits, P. (2011). Mechanisms linking social ties and support to physical and mental health. Journal of Health and Social Behavior, 52(2), 145-161. https://doi. org/10.1177/0022146510395592

Tsai, A., Tomlinson, M., Comulada, W., \& Rotheram-Borus, M. (2016). Food insufficiency, depression, and the modifying role of social support: Evidence from a population-based, prospective cohort of pregnant women in peri-urban South Africa. Social Science \& Medicine, 151, 69-77. https://doi. org/10.1016/j.socscimed.2015.12.042
Uchino, B. (2006). Social support and health: A review of physiological processes potentially underlying links to disease outcomes. Journal of Behavioral Medicine, 29(4), 377287. https://doi.org/10.1007/s10865-006-9056-5

Uchino, B., Bowen, K., Carlisle, M., \& Birmingham, W. (2012). Psychological pathways linking social support to health outcomes: A visit with the "ghosts" of research past, present, and future. Social Science \& Medicine, 74(7), 949957. https://doi.org/10.1016/j.socscimed.2011.11.023

Uchino, B., Trettevik, R., Kent de Grey, R., Cronan, S., Hogan, J., \& Baucom, B. (2018). Social support, social integration, and inflammatory cytokines: A meta-analysis. Health Psychology, 37(5), 462-471. https://doi.org/10.1037/hea0000594

Uchino, B., \& Way, B. (2017). Integrative pathways linking close family ties to health: A neurochemical perspective. American Psychologist, 72(6), 590-600. https://doi. org/10.1037/amp0000049.supp

Umar, E., Levy, J., Bailey, R. C., Donenberg, G., Hershow, R. C., \& Mackesy-Amiti, M. E. (2019). Virological non-suppression and its correlates among adolescents and young people living with HIV in Southern Malawi. AIDS and Behavior, 23(2), 513-522. https://doi.org/10.1007/s10461-018-2255-6

Vlassoff, C. (2007). Gender differences in determinants and consequences of health and illness. Journal of Health, Population and Nutrition, 25(1), 47-61.

West, N., Schwartz, S., Mudavanhu, M., Hanrahan, C., France, H., Nel, J., . . . Van Rie, A. (2019). Mental health in South African adolescents living with HIV. AIDS Care, 31(1), 117-124. https://doi.org/10.1080/09540121.2018. 1533222

Wu, T.-Y., Rose, S., \& Bancroft, J. (2006). Gender differences in health risk behaviors and physical activity among middle school students. The Journal of School Nursing, 22(1), 2531. https://doi.org/10.1177/10598405060220010501

Xiaowen, W., Guangping, G., Ling, Z., Jiarui, Z., Xiumin, L., Zhaoqin, L., \& Lin, L. (2018). Depression and anxiety mediate perceived social support to predict health-related quality of life in pregnant women living with HIV. AIDS Care, 30(9), 1147-1155. https://doi.org/10.1080/0954012 1.2018 .1456640

Yadav, S. (2010). Perceived social support, hope, and quality of life of persons living with HIV/AIDS: A case study from Nepal. Quality of Life Research, 19(2), 157-166. https:// doi.org/10.1007/s11136-009-9574-Z

Yeji, F., Klipstein-Grobusch, K., Newell, M.-L., Hirschhorn, L. R., Hosegood, V., \& Bärnighausen, T. (2014). Are social support and HIV coping strategies associated with lower depression in adults on antiretroviral treatment? Evidence from rural KwaZulu-Natal, South Africa. AIDS Care, 26(12), 1482-1489. https://doi.org/10.1080/09540121.2014.931561

\section{Author Biography}

Marisa Casale is an extraordinary professor at the University of the Western Cape's School of Public Health (SOPH) and an associate member of Oxford University's Department of Social Policy and Intervention. She is currently leading a work package focused on translating evidence into impact, within the UKRI GCRF Accelerating Achievement for Africa's Adolescents Hub (https://www.acceleratehub.org). 